\title{
Fault Characteristics Analysis of Industrial Robot Based on Fault Tree
}

\author{
Jian Jiao $^{\mathrm{a}}$, Xuejiao Zheng ${ }^{\mathrm{b}}$ \\ Chongqing Creation Vocational College, Chongqing 402160, China. \\ ahbxfhaha@126.com, b253773729@qq.com
}

Keywords: Industrial Robot, Fault characteristics, Predictive maintenance.

\begin{abstract}
In order to construct the predictive maintenance optimization model, this paper takes the robotic intelligent processing and production workstation as an example, and analyzes the fault characteristics of the equipment on the workstation and the fault characteristics of the key components. The failure characteristics of the equipment can be characterized and the fault characteristic parameters need to be monitored, and the failure threshold is finally determined. This method can make the multi-equipment system maintenance timing planning and processing to get a reasonable arrangement and organization.
\end{abstract}

\section{Introduction}

Fault tree analysis (FTA) is a logical reasoning method for fault events, which clearly illustrates the failure process of the system. Failure Modes and Effects Analysis (FMEA) is a qualitative logic inductive reasoning method $[1,2]$. It is a design method, which can effectively eliminate the hidden trouble in the equipment system design stage. The use of FTA or FMEA alone has its own shortcomings. It is easy to use the FTA to easily miss the bottom event, and the use of FMEA alone will increase the workload and easily lead to the failure of the failure mode and the analysis of the impact of the fault. However, if the fault tree analysis and reasonable combination of failure mode and impact analysis, the whole analysis process can be more based, but also to avoid duplication of the analysis.

For the running of industrial robots, the state of the robot system in a regular or continuous state monitoring and fault diagnosis to determine the status of the robot system to predict the future development trend of its state, based on its state of development trends and possible failure mode, in advance to develop a predictive maintenance plan, Determine the time, content, manner and necessary technical and material support that the robot should repair.

In this paper, the method of reverse comprehensive analysis is used to analyze the failure mode and fault characteristics of the robot automatic production line with the actual research situation.

\section{Analytical Method}

Due to the high degree of integration of the systems on the welding automation production line, the failure of one component will lead to the failure of the whole equipment. Therefore, this paper will mainly study the fault tree composed of OR gate.

Suppose the system has n bottom events $X_{i}$, and there are m minimum cut sets $K_{j}$. The fault tree is composed of $\mathrm{n}$ independent fault events, and both the bottom event and the top event are both occurring and do not occur. The structural function $\Phi(X)$ of the fault tree can be expressed as:

$\Phi(X)=X_{1} \cup X_{2} \cup \ldots \cup X_{\mathrm{n}}$

The probability of occurrence of event $X_{i}$ is $p\left(X_{i}\right)$, The probability of occurrence of the minimum cut set $K_{j}$ is $p\left(K_{j}\right)$, The probability of the fault tree event $p(T)$ can be obtained by the structural function of the fault tree is:

$$
p(T)=p\left(K_{1}+K_{2}+\ldots K_{m}\right)=\sum_{i=1}^{m} p\left(K_{i}\right)-\sum_{i<j=2}^{m} p\left(K_{i} K_{j}\right)+\ldots(-1)^{k-1} p\left(K_{1} K_{2} \ldots K_{m}\right)
$$


When the probability of occurrence of each bottom event in the fault tree is less than 0.01 , it can be approximated:

$$
p(T) \approx \sum_{i=1}^{m} p\left(K_{i}\right)
$$

The probability of introducing the i-th bottom event $X_{i}$ can be expressed as:

$$
I\left(X_{i}\right)=\frac{\partial p(T)}{\partial p\left(X_{i}\right)}
$$

The main purpose of calculating the importance of probability is to calculate the impact of each end event on the top event [4], so as to obtain the weak link of the system and determine the key fault bottom event. In order to carry out better maintenance work for system critical fault bottom events, The traditional FMEA analysis table mainly includes key end event, fault reason, fault characteristic parameter and Risk Priority Number $R P N$. The lower the $R P N$ value, the lower the risk of the failure mode, which includes three aspects: severity, incidence and difficulty, which are obtained by expert scoring. The analysis of the key end event FMEA table identifies the fault characteristic parameters that need to be monitored and analyzed. The RPN can be selected according to the characteristic parameters of the cloud platform data, thus determining the failure threshold of the fault feature parameters.

\section{Robot Production Line Fault Tree Establishment}

Industrial robot any key unit failure, it can't work, so the robot for multi-component series equipment. The same parts in different working conditions under the failure mode and failure of the system function performance is not the same? So only to understand all the various parts of the failure mode, in order to ensure that the fault tree analysis of the reasons for the failure of the system to improve the accuracy [5]. In this paper, the common failure modes of the common parts in the other equipment are given, and the main failure modes of the robot are given. Figure 1 shows the fault tree of the robot.

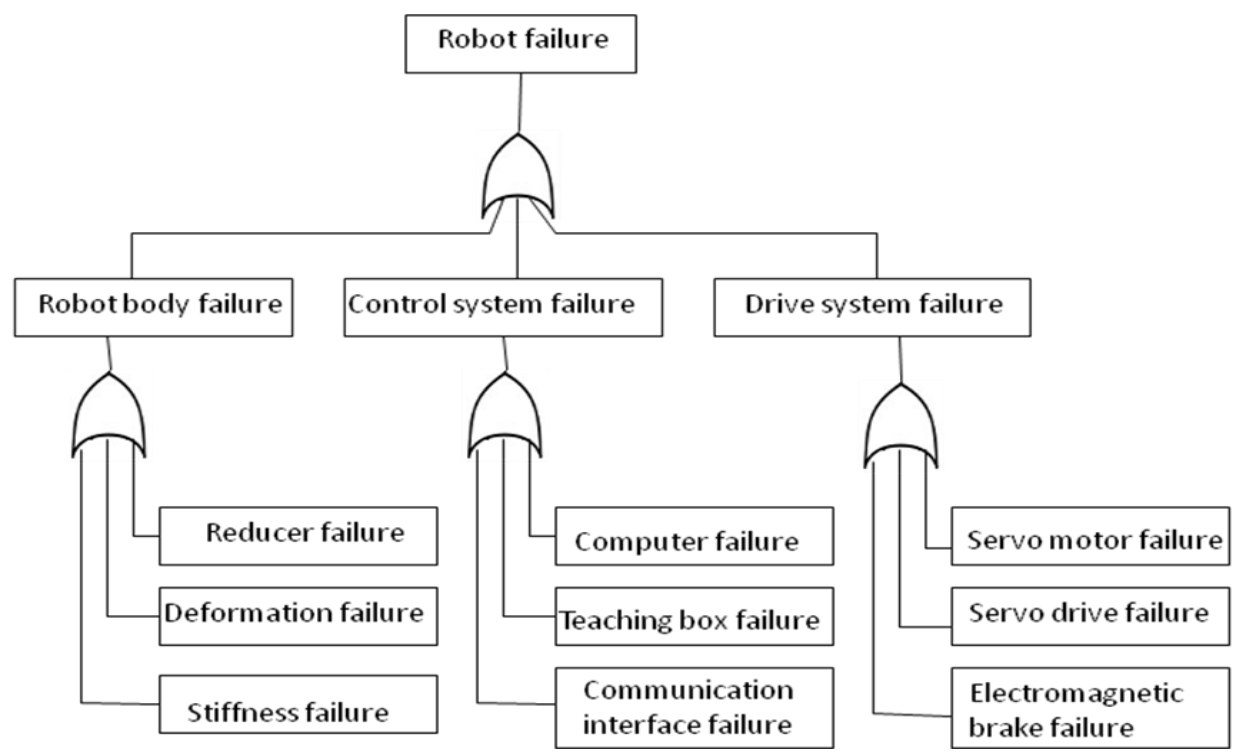

Fig. 1 Robot fault tree.

The failure of the fault tree, control computer, teaching pendant, servo motor, servo drive and electromagnetic brake failure can be further structural decomposition. Here only to explain the decomposition of the core of several core events [6], such as the reducer in the deep groove ball bearings failure $X_{2}$, gear teeth $X_{6}$, PCI failure $X_{16}$, motor encoder failure $X_{28}$, rotor winding burnout $X_{30}$ and so on.

In practical use, the various parts of the robot have high reliability, and the probability of occurrence of the bottom event is much less than 0.1. On the other hand, taking into account the logical 
relationship between the events at each end, and are mutually exclusive events, the bottom events can be considered as the smallest cut sets.

The probability of occurrence of the above event is 0.001 and the remaining event is 0.0001 . The failure probability of the robot top event is obtained according to the Eq. 3 by combining the qualitative analysis and quantitative analysis method for:

$$
p(T) \approx \sum_{i=1}^{m} p\left(K_{i}\right)=0.0121
$$

According to Eq. (4), the probability of the event $X_{2}, X_{6}, X_{16}, X_{28}, X_{30}$ is 1.0000, and the probability of the other end events can be calculated as 0.0010 . This determines that the event is a critical event.

Using the same method, get the fixture key end event: clamping arm loose $X_{40}$, regulating valve pressure instability $X_{42}$ and cylinder pneumatic components leak $X_{43}$; transmission equipment key end event: horizontal transmission speed abnormal $X_{50}$, gearmotor Output speed exception $X_{51}$; Welding equipment Key end event: torch failure $X_{60}$ respectively.

\section{Fault Feature Analysis and Fault Characteristic Parameter Determination}

According to the fault tree constructed above, the FTA method is used to qualitatively and quantitatively analyze the bottom event of the fault tree of the robot production line. The data for these end events comes from cloud platform data.

Table 1. Failure Mode and Impact Analysis of Critical Bottom Event

\begin{tabular}{|c|c|c|c|}
\hline Key End Event & Fault Reason & $\begin{array}{c}\text { Fault Characteristic } \\
\text { Parameter }\end{array}$ & $R P N$ \\
\hline $\begin{array}{l}X_{2}: \text { deep groove ball } \\
\text { bearings failure }\end{array}$ & the resonance of the bearing shaft & $\begin{array}{l}\text { Bearing maximum } \\
\text { amplitude }\end{array}$ & 61 \\
\hline$X_{6}$ :gear teeth & wear and fatigue failure & $\begin{array}{c}\text { Output parameter is } \\
\text { unstable }\end{array}$ & 43 \\
\hline$X_{16}:$ PCI failure & slot failure & $\begin{array}{l}\text { Output rate change } \\
\text { rate }\end{array}$ & 51 \\
\hline$X_{28}:$ motor encoder failure & $\begin{array}{l}\text { between the host computer and the connection } \\
\text { between the servo off }\end{array}$ & Command exception & 53 \\
\hline$X_{30}$ :rotor winding burnout & $\begin{array}{c}\text { rotor partial overheating; rotor coil expansion } \\
\text { blocked }\end{array}$ & The reliability & 64 \\
\hline$X_{40}$ :clamping arm loose & $\begin{array}{l}\text { clamping arm aging deformation, convex and } \\
\text { concave components are relatively dislocation }\end{array}$ & Wrong length & 69 \\
\hline $\begin{array}{l}X_{42} \text { :regulating valve } \\
\text { pressure instability }\end{array}$ & emissions holes have deposits & $\begin{array}{l}\text { Regulating valve } \\
\text { pressure }\end{array}$ & 82 \\
\hline $\begin{array}{l}X_{43} \text { :cylinder pneumatic } \\
\text { components leak }\end{array}$ & piston aging failure & Cylinder pressure & 86 \\
\hline $\begin{array}{c}X_{50} \text { :horizontal transmission } \\
\text { speed abnormal }\end{array}$ & gear rack engagement drive failure & Horizontal speed & 71 \\
\hline $\begin{array}{c}X_{51} \text { :Gearmotor Output } \\
\text { speed exception }\end{array}$ & the torque provided by the motor is too small & Output speed & 61 \\
\hline$X_{60}:$ torch failure & grinding the electrode head wear & Welder temperature & 72 \\
\hline
\end{tabular}


Due to the different contribution rate of the characteristic parameters in different failure modes, the minimum value is obtained according to the contribution rate of the characteristic parameters in different failure modes, and the minimum value is taken as the failure threshold of the failure characteristic parameters of each equipment, as shown in table 2.

Table 2. Failure threshold

\begin{tabular}{ccc}
\hline Device object & Fault characteristic parameter & Failure threshold \\
\hline industrial robot & rotor speed & $<8500 \mathrm{r} / \mathrm{min}$ \\
welding equipment & torch water pressure & $<0.4 \mathrm{MPa}$ \\
fixture & cylinder pressure & $0.2 \sim 0.8 \mathrm{MPa}$ \\
transmission equipment & deceleration motor output speed & $<6 \mathrm{r} / \mathrm{min}$ \\
\hline
\end{tabular}

\section{Summary}

Based on the reverse comprehensive analysis method, the fault tree of each equipment in the production line is established, and the key fault bottom events are listed by the fault tree analysis method, and the fault characteristics of each equipment need to be monitored are determined. Parameters and failure thresholds, which provide the basis for the subsequent construction and rational optimization of the predictive maintenance model.

\section{Acknowledgements}

This work was financially supported by the fund support scheme for young backbone teachers of Chongqing higher education.

\section{References}

[1]. He Xin, Yang Shunkun, Liu Bin.Fuzzy Software Fault Diagnosis Model and Application Based on FMEA / FTA [J]. Computer Measurement And control, 2009, 17 (1) , p.42-45

[2]. Bai Xu, Sun Liping, Sun Hai, et al. Risk analysis of marine structure hoisting and transportation process based on FMFA and FTA [J].Shipbuilding, 2012, 53 (4) , p.173-175

[3]. Ma Haifeng, Liu Songliang, Xu Wei.Study and research on the life index of airborne equipment [J]. Aircraft Design, 2007, 27 (2) , p.54-58

[4]. Wang Ruifang, Liu Lin, Xu Fang .Research on Prognostics Technology of Robot System Based on Statistical Process Control[J]. MACHINE TOOL \& HYDRAULICS, 2009, 37(6)) , p.227-230

[5]. Su Jinyuan.Study on reliability of industrial robot system based on fault tree [D]. Hengyang: Nanhua University, 2013

[6]. Wang Gaiyun, Liang Fen, Zhu Mingri, et al. Reliability analysis of welding robot based on fault tree [J]. Microcomputer Information, 2008, 24 (17), p.272-273 